\title{
Research on Constructing Method of Intellectual Property Talent Cultivation Base in University
}

\author{
Yan LIU \\ Intellectual Property Center of Harbin Engineering University, Harbin 150001, China
}

\begin{abstract}
Constructing of intellectual property talent cultivation base in university is researched in this paper. According to the deficiencies of traditional modes for talent cultivation in Chinese universities and the social requirement for compound IP talent, a constructing thought of "one two three four five" is proposed based on the standardized and institutionalized principles to accelerate constructions of IP talent training base. The platform constructions, teaching staff and system constructions of the base are introduced detailedly. Different training programs for different types of IP talents are designed and proposed which can realize the purpose of compound IP talent training.
\end{abstract}

KEYWORD: Intellectual Property; Talent Training; Talent Base Constructing

\section{INTRODUCTION}

"National Intellectual Property Strategy" is promulgated in China in 2010, stresses construction of IP (intellectual property) talent teams and put IP human resources as one of the important tasks for current country IP strategy implementation. College as the important place of talent training, it has also became a base of national implementation of IP strategy[1].

This paper studied the domestic and foreign IP talent training mode, investigated IP training methods of other colleges and summed up how to build an effective IP talent training base. IP talents training modes are accumulated by practice and training contents for different types of IP talent are summarized.

In recent years, with the China increases publicity and popularization of education of IP, many IP talents training modes have emerged in different periods. At present, according to the relevant literature [2-5], most researchers are focusing on diploma education and degree education about the mode of IP students training in colleges and universities. The establishment of IP major or setting up a IP college need a large number of qualified teachers, and the approval of relevant departments after a long time argumentation [6]. IP training in domestic needs use a lot of resources, regardless of the traditional model of construction institute of IP, or multi construction of IP culture base pattern[7-8].

\section{CONSTRUCTING GUIDING IDEOLOGY}

The born of the university IP talent in education or training base in line with the social advantages of resources allocation principle, can cultivate the practice talent of IP. Meanwhile it also can provide helps to develop compound talents. This will be one of the effective modes of colleges and universities to train IP talents in the next period.

IP talent education base should be combined with the actual situation of the school, to establish core of IP practice ability training, and the tenet of compound talent training. In addition talent training systems also must be established, to expedite the speed of IP compound talents training.

IP talent education base construction process should be around the target of IP talent training, and the philosophy of IP compound talents training. a constructing thought of "one two three four five" is proposed based on the standardized and institutionalized principles to accelerate constructions of IP talent training base. The "one two three four five" thought is that:

- "one-dependent": an IP management agency as the dependent;

- "two-systems": theory and practice talent training systems as the cores;

- "Three-objectives": enhancing IP protection ability, theory with practice ability and innovation ability as the goals; 
- "four-combinations": combination of self management and teacher training; combination of theory and practice; combination of curricular and extracurricular teaching, combination of school and outside school practice base;

- "Five-platforms": IP learning platform, IP research platform, IP practice platform, IP publicity platform and IP innovation platform.

\section{TALENT BASE CONSTRUCTION}

There are two aspects of constructing college IP talent base (see Figure 1). One is the base platform construction. Two is system and teaching staff construction.

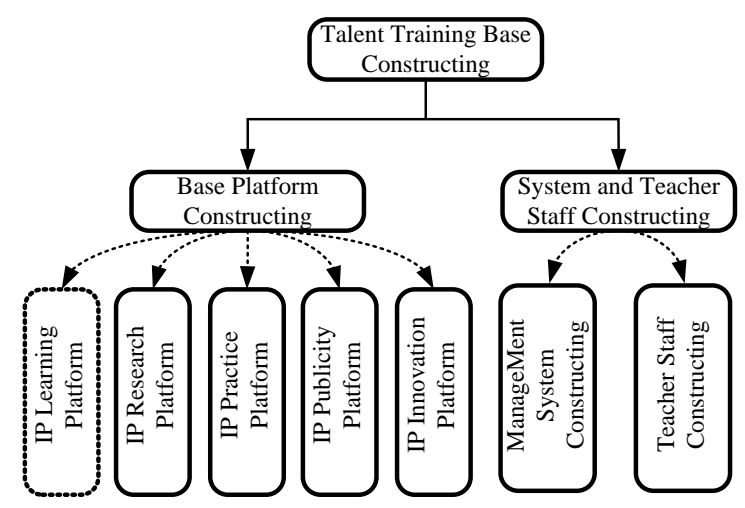

Figure 1. Composition of university IP talent training base constructing

\subsection{Base platform constructing}

\subsubsection{IP learning platform}

This platform enriches the students' IP knowledge and awareness mainly by self-study, regular training, expert lectures and other ways.

Useful books are recommended for students, such as patent law and its implementation rules, IP conspectus, IP law cases, etc. In addition, students are also encouraged to learn more knowledge using Chinese IP remote education platform. There are centralized training, case discussion and other forms in regular training which provide ways for teachers and students communicating to strengthen the students' understanding for IP.

\subsubsection{IP research platform}

Mainly task of this platform is to research IP strategy analysis and warning analysis of IP. This platform aims to make student use knowledge of IP to solve problems in learning and research, where students can obtain real exercises. So, guiding teachers can help students research from the shallower to the deeper, help students make consciousness of IP in the scientific research based on the students' professional.

\subsubsection{IP practice platform}

This platform's purpose is to enhance the ability of students for patent agent. There are many social investigation activities in this platform, such as practicing in the school IP office, patent firms, law firms and other practices, which is the highlight difference from traditional IP talents training mode. Students in this platform can personally experience what is IP and how to do the patent agency by practice learning. It is worth noting that, in the social practice course, it needed to strengthen students' consciousness for protecting business secrets and not disclosing related business information to other people or institutions.

\subsubsection{IP publicity platform}

Making more students know about IP and joining in IP protection voluntarily are the most important tasks of this platform. Every in the base will be a best propagandist and their growth and achievements both will be best publicity cases. So, this platform mainly engaged in publicizing the importance of IP protection and rich activities in the base.

\subsubsection{IP innovation platform}

The platform provides student IP forum and IP rights service teams with the purpose of encouraging them to organized IP activities spontaneously. Meanwhile self entrepreneurship is encouraged with some funding by the base. IP innovation platform can works together with school committee to provide IP service for innovation competition and activities to inspire students' enthusiasm and innovation. At the same time, the base can provide financial for supporting of the self entrepreneurship for deepening IP practices contents.

\subsection{System and teaching staff constructing}

As the important IP talent training place, scientific, systemic, executable management system must be established to ensure that the training base can works effectively.

\subsubsection{Management System Constructing}

The management system of university IP talent training base includes following aspects: responsibilities, construct and management, job contents, employee rating, employee rewards and punishment, and so on. However, detail management ordinances must be established according to actual situation of each university.

\subsubsection{Teaching Staff Constructing}

According to the particularity of compound IP talent training, the teachers in IP talent training base are different from other professional teachers in 
colleague. The teacher staff for the base can be constructed by forms of training, introducing and engaging. On the one hand, teachers of IP management in the university can conduct students' theory knowledge learning and social practices. And, they can improve their professional level by vocational study, specialized training and patent agent test. On the other hand, home and abroad famous professors, experts who are engaged in IP research and leaders, managers and lawyers who are engaged in IP practices can be invited to give lectures. It can let the teachers and students know the newest trends of IP technology field and legal field. Meanwhile, teachers and students can also obtain IP practices by listening to the lectures.

\section{TALENT TRAINING PROGRAM}

According to the actions in the social and economy, IP talents usually can be classified to four types: IP creation talents, IP research talents, IP management talents and IP practice talents. Students trained by conventional IP education can not meet the current social requirement for compound IP talents. Different IP talents should adopt different training modes and plans. So, simple, executable IP talents training modes and different training contents according different talent types are improved in this paper.

\subsection{Talent training modes}

\subsubsection{Concentrated lecturing and special training combined mode}

For the students with same or similar specialty direction, Concentrated lecturing mode is suitable. The lecture contents include patent application principle, procedure, method, and so on. Key patent licensing conditions, as an example, can adopt special training mode by simple but profound introduction. If necessary, cases analyzing is used to guide students to understand the basic contents of patent systems, correctly judge the typical categories of patent torts and correctly distinguish the ambit between rational and tort behaviors

\subsubsection{Group discussion mode}

MBA teaching mode for reference, the students are divided in to several groups and each group is assigned to discuss and analyze a patent case. At last, discussion and analysis results of each group are shared and discussed amount all groups.

\subsubsection{Simulation teaching mode}

Simulation teaching is an effective mode to improve the practice ability of students. Some students simulate the formal examinants to carry out formal examination for patent application. Some students simulate the actual examinants to carry out examination of patent novelty, creativity and practicality. Some students simulate the applicants for patent writing. By the demonstration of patent application and examination, all students simulated as applicants and examinants can be familiar with the procedure of patent application and examination.

\subsubsection{Pair guidance mode}

Pair guidance mode is suitable for single patent case. Writing a patent taken self scientific research as background, the students communication and discuss with teachers face to face. Using this manner, the students can obtain more directly and intuitive helps. They can deeply understand the basic requirement of patent law and implementing regulations.

\subsection{Talent training contents}

IP talent cultivating object (students) in accordance with their development aspirations is divided into IP creation talent, IP research talent, IP practice talent, different types of talents have taken different training content.

\subsubsection{Training contents for IP creation talents}

The IP creation talent in this paper mainly refers to the students who participating in scientific research activities and innovative activities. Students in the learning and researching process often do not care about the importance of protecting IP, so that many techniques missed the best time of the protection, and many patent techniques lost novelty because of that it has been published in the paper. The content of this people's training mainly include that : the basic knowledge of patent law, patent information retrieval and utilization, writing application documents of patent and protecting technical secrets. Through learning, this part will help to plan layout of IP advanced, promoting IP accumulation, so as to effectively protect IP.

\subsubsection{Training contents for IP research talents}

The research talents in this paper mainly refer to students who engaged in the legal system, the macro strategic research on theory and Countermeasures, they are law professional students mainly come from the economics and management college or the humanities college. So for these students, the main training contents should be: Patent Law and related law, patent protection typical cases, and typical case analysis of patent litigation, so that to deepen the theoretical knowledge, and to increase the content about patent law in real teaching. 


\subsubsection{Training contents for IP management talents}

As an important branch of IP field, IP management is an interdisciplinary with knowledge integration. Current IP talent training mode is still a conventional magistral mode. The most lectures in current training are still law course. However, for a student who will engage in IP management job in a corporation, only knowing the IP law knowledge is very not enough. Management knowledge associate with IP is should be known and researched. So, the training contents for IP management talents include: patent law basic knowledge; patent application and approval procedure; patent information searching, analysis and utilization; patent administerial protection; corporation patent management system constructing and corporation patent strategy.

\subsubsection{Training contents for IP practice talents}

IP practice talents are also compound talents with IP knowledge and engaging in IP correlative jobs. According to the difference of detail job contents, the practice talents are divided into law affair talents; intermediary service talents and agent practice talents.

a) IP law affair talents training contents

IP law affair talents are mainly refer to peoples who engage in lawyers and judges. So, law knowledge is very important for them and three laws are must mastered: copyright law, patent law and trademark law. Meanwhile, the following skills are also needed to master, including: international trade and IP international protection; patent literatures searching, IP damages; home and abroad patent cases trial comparison. In the training process, it is important to train the students to know IP law system, common law system and relevant policy system. Then the students can have the ability of analysis method and technology for law. They also have the ability of solving and dealing with IP lawsuit using IP knowledge.

b) IP intermediary service talents training contents

Intermediary service institutions can contribute to transform of the scientific and technological achievements. IP intermediary service talents are different from general intermediary services people, they not only need to master the domestic IP laws and regulations and the relevant business, but also they should be familiar with international rules and the major trading partners of IP law and practice skills. Therefore, the specific training contents of IP intermediary service personnel should include: the new development of Patent Law, the patent application and examination in the field of modern technology (information technology, biotechnology, software, etc.), the patent information analysis, patent licensing and assignment by practice, and standard of patent technology. c) IP agent practice talents contents

IP agency personnel mainly refers to the patent agents, patent agent is a compound talent with patent law and patent technology knowledge in him. Due to they often deal with new and high technology, patent agents must to master related technology, understand the relevant laws, have higher writing expression ability, have the ability to analysis and solve problems, so as to clearly, accurately to write patent application and provide other services, and also should master at least one foreign language.

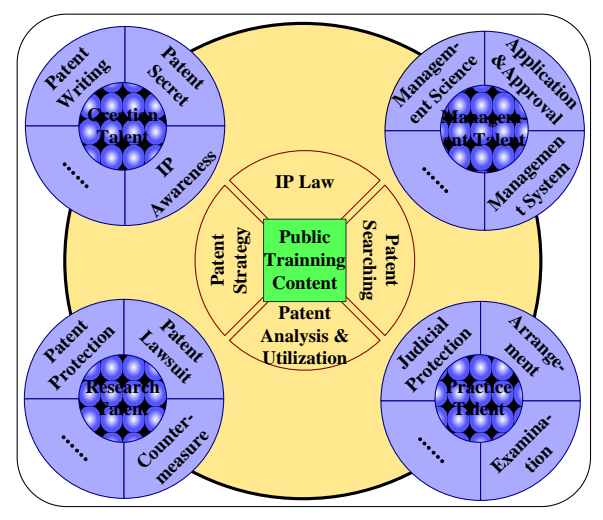

Figure 2. Training contents for different IP talent types

In summary, the IP talents training should be based on the characteristics and different training objectives plan special content just shown in Figure 2. However, no matter what kind of content of talents cultivation, we need to deal with the composite problem of the theoretical knowledge and practical ability. Generally speaking, IP training should not only pay attention to the students ' IP related theoretical knowledge, but also to strengthen practical ability of IP technology practice, management practice and legal practice.

\section{REFERENCES}

[1]Jin Xiaodong. Building an innovation oriented country and the training of talents of IP in China. Productivity research, No.11.2011:106-107.

[2]Yuan Zhenfun. IP talent education: status quo, problems and trends. Building of IP culture. 2013,10:49-52.

[3]Kang Jianhui, Ma Yan. Research on the training mode of talents in Colleges and universities of Shaanx. The special economic zones,2008,(7):214-216.

[4]Yang Deqiao. Science and Engineering Research on the strategy of IP talent cultivation in Colleges and Universities. The higher education of Sciences. 2011(1):56-67.

[5]Du Jing. Discussion on IP talent training in University. Liaoning administrative college newspaper, 2007,9(3):123124.

[6] Xu Ling, Wu Yanan. Research on the training mode of university IP. The theory of observation,2014,(2):132-133.

[7]Chen Meizhang. Thinking of university IP education and talent cultivation of the Chinese. IP rights, 2006,(1):1-10.

[8]Wang Guanling, Sun Xinzhu, Yang Jun. Exploration of teaching reform of University IP Research Based on. Chinese Power Education, 2014,(3):111-112. 